\title{
Volatility of Simulated High-Level Nuclear Waste Glass by Thermogravimetric Analysis
}

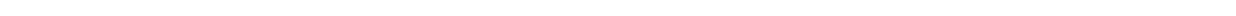

Westinghouse Savannah River Company, Savannah River Site, Aiken, South Carolina 29808

\begin{abstract}
The volatilities of simulated, high-level nuclear waste glasses have been measured using thermogravimetric analysis (TGA). These volatilities were measured in the region of the glass transition temperature $\left(T_{\mathrm{g}}\right)$ of the waste glasses, which is between $450^{\circ}$ and $500^{\circ} \mathrm{C}$. These data were obtained because the Waste Acceptance Preliminary Specifications require that no foreign materials be released into the canistered waste form upon heating of the canister to this glass transition temperature. In fact, all of the waste glass samples studied actually exhibited a net weight gain upon heating. This weight gain was shown to be due to oxygen uptake through oxidation of FeO. Powdered glass samples did show a small weight loss which was smaller in magnitude than the weight gain and was associated with water desorption. No true volatility was detected to the level of sensitivity $(0.01 \mathrm{wt} \%)$ of the TGA instrument. This converts to a sensitivity of $330 \mu \mathrm{g} / \mathrm{m}^{2}$ of glass surface and a corresponding minimum value of $41 \mathrm{mg}$ of volatiles for each Defense Waste Processing Facility canistered waste form. TGA experiments carried out at higher temperatures $\left(800^{\circ} \mathrm{C}\right)$ revealed that organic concentrations in the waste glasses are less than $0.01 \mathrm{wt} \%$. Thus, these results demonstrate that the Defense Waste Processing Facility will be able to comply with the Waste Acceptance Preliminary Specifications on the exclusion of foreign materials from the canistered waste forms, after exposure to $T_{\mathrm{g}}$. [Key words: glass, nuclear waste, volatility, thermogravimetry, models.]
\end{abstract}

\section{Introduction}

T Ee Department of Energy has 130 million liters of highlevel nuclear waste stored in carbon steel tanks at its Savannah River Site. The Defense Waste Processing Facility has been constructed in order to convert this alkaline slurry into a durable borosilicate glass which is poured into a stainless steel canister and sealed. The sealed canister is then transported to the Glass Waste Storage Building at the Savannah River Site for temporary storage prior to transfer to the Department of Energy's Office of Civilian Radioactive Waste Management for shipment to the federal repository.

The Office of Civilian Radioactive Waste Management established a Waste Acceptance Committee to develop a process for acceptance of high-level nuclear waste from Department of Energy defense facilities. As part of this process, this committee produced the Waste Acceptance Preliminary Specifications,' which detail the requirements that must be met before Office of Civilian Radioactive Waste Management will accept the canistered waste forms. Westinghouse Savannah

C. M. Jantzen-contributing editor

Manuscript No. 196637. Received June 17, 1991; approved November 12, Ma1.

Prepared in connection with work done under Contract No. DE-AC0989SR18035 with the U.S. Department of Energy. By acceptance of this paper, the publisher and/or recipient acknowledges the U.S. Government's right to retain a nonexclusive, royalty-free license in and to any copyright covering this paper, along with the right to reproduce and to authorize others to reproduce all or part of the copyrighted paper.
River Company has detailed the strategy for demonstrating compliance with the Waste Acceptance Preliminary Specifications in its Waste Form Compliance Plan ${ }^{2}$ for the Defense Waste Processing Facility.

The Waste Acceptance Preliminary Specifications prohibit foreign materials within the canistered waste forms. These foreign materials include free gases, free liquids, explosives, pyrophorics, combustibles, and organics. In addition, it is specified that these foreign materials must not be released or generated as a result of exposure of the canistered waste form to the glass transition temperature $\left(T_{\mathrm{g}}\right)$ of the waste glass. For waste glass produced at the Defense Waste Processing Facility at Savannah River Site, $T_{\mathrm{g}}$ will be between $450^{\circ}$ and $500^{\circ} \mathrm{C}$.

These foreign materials can potentially exist either in the waste glass itself or within the free volume of the canister. (The canister free volume is that volume of the canister not occupied by waste glass. Characterization of the gas within the free volume of prototypical canistered waste forms is the subject of a separate study. ${ }^{3}$ ) This report focuses on the search for any foreign materials which are released as the waste glass is heated to $T_{\mathrm{g}}$. The technique of thermogravimetric analysis (TGA) was used to detect volatility of the waste glass as it is heated up to $T_{\mathrm{g}}$. Experiments at temperatures several hundred degrees above $T_{\mathrm{g}}$ were also carried out to determine the nature of volatility as a function of temperature.

Reports on the volatility of waste glasses have previously appeared in the literature. Gray ${ }^{4}$ has shown that volatility from simulated high-level radioactive waste glasses is not significant below $1000^{\circ} \mathrm{K}$. An extrapolation of his data to $500^{\circ} \mathrm{C}$ $\left(\sim T_{\mathrm{g}}\right)$ gives a weight loss of $0.01 \mathrm{mg} / \mathrm{m}^{2}$ of glass surface. Walmsley et $a l .{ }^{5}$ have also measured weight loss as a function of temperature for a borosilicate glass. Extrapolation of their data to $500^{\circ} \mathrm{C}$ gave a glass volatility of $0.24 \mathrm{mg} / \mathrm{m}^{2}$. Wilds ${ }^{6}$ measured weight loss from a sodium borosilicate glass containing simulated sludge. Wilds had to heat the glass to $900^{\circ} \mathrm{C}$ for $3 \mathrm{~h}$ before a weight loss $\left(0.02 \mathrm{mg} / \mathrm{m}^{2}\right)$ could be detected. Using a gamma radiation scanning method, Kamizono et al. ${ }^{7-9}$ detected ${ }^{137} \mathrm{Cs}$ and ${ }^{106} \mathrm{Ru}$ volatiles. This extremely sensitive technique revealed that volatilities of these two radionuclides were extremely low at $500^{\circ} \mathrm{C}$. Actual detected values were $0.7 \times 10^{-9} \mathrm{mg} / \mathrm{cm}^{3}$ for ${ }^{137} \mathrm{Cs}$ and $\sim 0.1 \times 10^{-9} \mathrm{mg} / \mathrm{cm}^{3}$ for ${ }^{106} \mathrm{Ru}$. Since sodium and lithium metaborates (see below) are an order of magnitude more volatile than cesium, the volatilities of these species will be at least one order of magnitude greater than the cesium volatility.

Hastie, Bonnell, and Plante ${ }^{10,11}$ used Knudsen effusion and transpiration mass spectrometry to monitor glass volatility as a function of temperature. They found that the volatile species generated were mainly sodium, lithium, and cesium metaborates. This work has been confirmed by the mass spectrometric work of Asano and Yasue, ${ }^{12,13}$ Asano and Kou, ${ }^{14}$ Shultz et al., ${ }^{15}$ and Wilds. ${ }^{16}$ Wenzel and Sanders ${ }^{17}$ used atomic absorption spectroscopy to measure volatilities and found no dependence of the volatility on relative humidity, a finding which is consistent with the research of Hastie et al. ${ }^{10,11}$ Terai and Kosaka ${ }^{18}$ also observed metaborate volatiles between $900^{\circ}$ and $1300^{\circ} \mathrm{C}$. Extrapolation of their volatility data to $500^{\circ} \mathrm{C}$ gave $10^{-6} \mathrm{~g} / \mathrm{cm}^{2} / \mathrm{d}$. 
It is clear from the above studies that the volatilities of simulated high-level nuclear waste borosilicate glasses are very low and that temperatures of $\sim 800^{\circ} \mathrm{C}$ are required to achieve detectable levels of volatiles (except for the work of Kamizono et $\left.a l^{7-9}\right)$. Extrapolated volatilities at $T_{\mathrm{g}},\left(\sim 500^{\circ} \mathrm{C}\right)$, estimated from the data presented above, are very small but vary over several orders of magnitude. However, the Waste Acceptance Preliminary Specifications require volatility data at $T_{\mathrm{g}}$, from Defense Waste Processing Facility waste glass. TGA experiments were therefore carried out on Defense Waste Processing Facility simulated high-level nuclear waste glasses produced at the Savannah River Site in a temperature range which includes $T_{\mathrm{g}}$. This report details the results of these experiments and provides evidence for a lack of glass volatility (to the sensitivity of the TGA instrument) at $T_{\mathrm{g}}$.

\section{Experimental Procedure}

TGA experiments were carried out using a Du Pont 951 thermogravimetric analyzer and 2100 thermal analyzer. Samples $(\sim 100 \mathrm{mg})$ were placed in platinum boats. The purge gas was either helium, oxygen, or air. The flow rate was normally 0.4 standard cubic feet per hour $\left(1 \mathrm{ft}^{3} \sim 2.83 \times 10^{-2} \mathrm{~m}^{3}\right.$. The samples of simulated waste glass were subjected to two different temperature cycles, profile $1\left(\right.$ to $500^{\circ} \mathrm{C}$ ) and profile 2 (to $800^{\circ} \mathrm{C}$ ).

In the temperature profile referred to as profile 1 , the sample is heated to $450^{\circ} \mathrm{C}$ at a rate of $10^{\circ} \mathrm{C} / \mathrm{min}$. It is held at $450^{\circ} \mathrm{C}$ for $10 \mathrm{~min}$ and then slowly ramped at a rate of $0.5^{\circ} \mathrm{C} / \mathrm{min}$ to $500^{\circ} \mathrm{C}$. After a $10-\mathrm{min}$ holding period at $500^{\circ} \mathrm{C}$, the sample is cooled to room temperature using the reverse of the profile used for sample heating. The objective here was to ensure that the glass sample was heated within the region of $T_{\mathrm{g}}$ for at least $4 \mathrm{~h}$.

In temperature profile 2 , the sample is ramped from room temperature to $800^{\circ} \mathrm{C}$ at a rate of $10^{\circ} \mathrm{C} / \mathrm{min}$ (most of these sample runs included a 3-h hold at $60^{\circ} \mathrm{C}$ ) and then held at $800^{\circ} \mathrm{C}$ for $10 \mathrm{~min}$ before being cooled at a rate of $10^{\circ} \mathrm{C} / \mathrm{min}$. The profile is then repeated (without the 3-h hold period).

Glass samples were obtained from canisters which had been filled during large-scale pilot plant campaigns, referred to as scale glass melter (SGM) campaigns, at the Savannah River Site with one exception. The glass sample from SGM 8 was intercepted between the melter pour spout and the canister nozzle. The SGM campaigns used a variety of simulated borosilicate waste glasses. ${ }^{19}$ The eighth SGM campaign (SGM 8) used black frit 165, which contains simulated sludge but no precipitate hydrolysis aqueous product simulant. All of the other campaigns used a simulated glass frit/sludge/precipitate hydrolysis aqueous feed spiked with various levels of organics to cover the expected range of organics which will be present during the running of the Defense Waste Processing Facility.

Black frit 165 contains the following components, ${ }^{19}$ in wt\%: $\mathrm{SiO}_{2}(55), \mathrm{B}_{2} \mathrm{O}_{3}(7.2), \mathrm{Li}_{2} \mathrm{O}(5.0), \mathrm{Na}_{2} \mathrm{O}(11), \mathrm{MgO}(0.7), \mathrm{CaO}$ (1.4), $\mathrm{ZrO}_{2}$ (0.7), $\mathrm{Fe}_{2} \mathrm{O}_{3}$ (11.3), $\mathrm{Al}_{2} \mathrm{O}_{3}$ (4.3), $\mathrm{MnO}_{2}$ (2.5), and $\mathrm{NiO}(0.9)$. A typical coupled-feed glass ${ }^{19}$ containing $65.4 \%$ frit, $26.6 \%$ sludge, and $8.0 \%$ precipitate hydrolysis aqueous feed contains the following components, again in wt $\%: \mathrm{SiO}_{2}$ (49.1), $\mathrm{B}_{2} \mathrm{O}_{3}$ (10.1), $\mathrm{Li}_{2} \mathrm{O}$ (3.2), $\mathrm{Na}_{2} \mathrm{O}$ (10.1), $\mathrm{MgO}$ (1.3), $\mathrm{CaO}$ (0.9), $\mathrm{Fe}_{2} \mathrm{O}_{3}(11.7), \mathrm{Al}_{2} \mathrm{O}_{3}(4.7), \mathrm{MnO}_{2}$ (3.2), $\mathrm{NiO}(1.0), \mathrm{TiO}_{2}$ (1.3), $\mathrm{K}_{2} \mathrm{O}(3.2), \mathrm{Cs}_{2} \mathrm{O}(0.06)$, and $\mathrm{SrO}(0.05)$.

The glass samples were analyzed with the thermogravimetric analyzer as both glass pieces and glass powders. The glass powders were created by milling the larger glass pieces, using a mechanical grinder (Tekmar grinding mill with a tungsten carbide blade), and then collecting only those particles which passed through a 200 -mesh screen. Glass pieces were fragments less than $100 \mathrm{mg}$. Typically, from one to five glass pieces were used to give a loading of $\sim 100 \mathrm{mg}$.

Calcium oxalate monohydrate from Du Pont was used as the "standard" for TGA experiments. Calcium oxalate mono- hydrate provides a reference to show that the instrument is operating effectively and checks the stability of the instrument over time. This material was run at the beginning, end, and once during the middle of data acquisition. The TGA curve showed the expected weight losses within experimental error for this material. The values determined were $12 \%$, $18 \%$, and $31 \%$ for the three different weight loss regions. The corresponding weight losses reported by Du Pont ${ }^{20}$ are $12.5 \%$, $18.5 \%$, and $30.3 \%$.

The temperature ranges of the three weight losses using calcium oxalate monohydrate also provide a general indication of proper temperature calibration. The most important temperature range for the purpose of this study includes the glass transition temperature, $T_{\mathrm{g}}$, of the glass, which is between $450^{\circ}$ and $500^{\circ} \mathrm{C}$. This corresponds to the second temperature range for calcium oxalate monohydrate, which has been reported in the literature as $405^{\circ}$ to $523^{\circ} \mathrm{C},{ }^{20} 400^{\circ}$ to $500^{\circ} \mathrm{C},{ }^{21}$ and $400^{\circ}$ to $500^{\circ} \mathrm{C}^{22}$ This can be compared to the range observed in these experiments of $390^{\circ}$ to $490^{\circ} \mathrm{C}$. This indicates that the temperature reported on the TGA curves for this work is $-10^{\circ}$ to $20^{\circ} \mathrm{C}$ lower than the actual temperature. The third temperature range for these experiments was significantly less than reported by others. The range for this study was $565^{\circ}$ to $700^{\circ} \mathrm{C}$ versus reported values of $626^{\circ}$ to $793^{\circ} \mathrm{C},{ }^{20} 660^{\circ}$ to $830^{\circ} \mathrm{C}$, ${ }^{21}$ and $620^{\circ}$ to $850^{\circ} \mathrm{C}$. ${ }^{22}$ This indicates that for TGA curves using profile 2 , the temperature indicated in the plot underestimates the actual temperature by $-100^{\circ} \mathrm{C}$. The data are presented in this paper without correcting for this divergence, since it does not alter the conclusions of this work regarding volatility.

The TGA curves obtained from calcium oxalate monohydrate at the beginning and near the middle of the experimental period were essentially identical. The calcium oxalate monohydrate run at the end, however, showed a second temperature range of $400^{\circ}$ to $500^{\circ} \mathrm{C}$ and a third range of $610^{\circ}$ to $725^{\circ} \mathrm{C}$. These changes reduced the difference between actual and measured temperatures discussed above.

In terms of absolute values of weight, the TGA underestimates the true value by $4.1 \%$. This was determined using a calibrated set of weights. Hence, an observed weight change in these experiments of $400 \mu \mathrm{g}$ translates to an actual change of $384 \mu \mathrm{g}$. Since this correction is close to the detection limit of the apparatus, no corrections were made to the weight changes recorded in this report.

The scanning electron microscopy data were obtained on an ISI Model DS-130 scanning electron microscope. Polystyrene spheres of diameter equal to $29.64 \pm .06 \mu \mathrm{m}$ were added to the glass samples as an internal standard. The spheres were obtained from NIST, as SRM 1961.

A Leeds and Northrup Microtrac II, model 158704 laser light scattering instrument was used to obtain the particle size distribution. The glass powder was dispersed $(-0.3 \mathrm{~g}$ of glass in $25 \mathrm{~mL}$ ) in a 0.6 vol\% $\mathrm{Na}_{2} \mathrm{HPO}_{4}$ aqueous solution (distilled water). This was subsequently diluted in distilled water $(-25 \mathrm{~mL})$ and placed in the sample cell. The "standard" used was an alumina powder, whose particle size distribution had not changed significantly for the past few months.

The BET data were acquired using a Digisorb $2600 \mathrm{BET}$ adsorption surface area analyzer by Micromeritics. A "standard" sample of alumina was used and a surface area of $0.468 \mathrm{~m}^{2} / \mathrm{g}$ obtained. The expected value for the alumina is $0.47 \pm 0.02$

The $\mathrm{Fe}^{2+} / \mathrm{Fe}^{3+}$ ratios were determined colorimetrically using the procedure developed by Baumann. ${ }^{23}$ The experiments were performed using a Hewlett-Packard 8451 diode array spectrophotometer.

\section{Results}

\section{(1) Powder Characterization}

This TGA study of simulated waste glasses used two types of samples. The first type, referred to as glass pieces, was 
small fragments of glass which had been removed from the canisters. The other type of glass sample was powder. This milling of the larger glass pieces into a powder was done in order to increase the surface area of the glass sample. This is important because volatilization from the surface is the expected mechanism for weight loss at temperatures near $T_{\mathrm{g}}$. The milling produced a polydisperse powder, and only that portion of the powder which passed through a 200-mesh filter was collected. Figure 1 shows a scanning electron micrograph of the milled glass containing some added $\sim 30-\mu \mathrm{m}$ latex spheres for reference. A determination of the particle size distribution by laser light scattering revealed a mean diameter of the volume distribution that ranged from 43 to $60 \mu \mathrm{m}$. The BET surface areas ranged from 0.23 to $0.39 \mathrm{~m}^{2} / \mathrm{g}$.

\section{(2) TGA Results}

A typical TGA curve for a simulated waste glass (produced during the seventh SGM campaign) subjected to profile 1 (see Experimental Procedure section) is shown in Fig. 2. The curve shows the change in weight of the sample, in weight percent, as a function of temperature. This particular powdered sample of $\sim 100 \mathrm{mg}$ was purged with oxygen during the heat treatment. From this curve, it is evident that the glass sample has actually gained weight as a result of this heat treatment. The apparent weight gain (measured after the sample has cooled back down to $25^{\circ} \mathrm{C}$ ) is $\sim 430 \mu \mathrm{g}$ or $0.43 \mathrm{wt} \%$. Figure 3 gives the same data except that the change in weight is plotted against time.

The slope of the cooling portion of this curve $(3 \times$ $10^{-4} \mathrm{wt} \% /{ }^{\circ} \mathrm{C}$ ) is the baseline change with temperature and is reproducible (i.e., if the sample is subjected to the same temperature profile a second time, the curve will follow this slope during both heating and cooling). This implies that (1) no further changes are occurring upon additional heat treatment and (2) the baseline is not flat.

Since the initial slope for the heating cycle is less than this baseline slope, the data also reveal that this particular sample must be losing weight during the initial heating of this powdered glass sample.

Figure 4 shows the type of curve obtained using profile 2 for a powdered sample of SGM 7 with oxygen purging. The weight gain $(-570 \mu \mathrm{g})$ has plateaued by $\sim 650^{\circ} \mathrm{C}$, with the repeat cycle demonstrating that no additional weight change has occurred. This plot reveals that the scatter in weight after reaching saturation is $\sim 10 \mu \mathrm{g}(0.01 \%)$ as measured after the sample has returned to room temperature. An initial weight loss is also evident with profile 2, since the slope of the initial heating curve is less than the slope of the cooling curve.

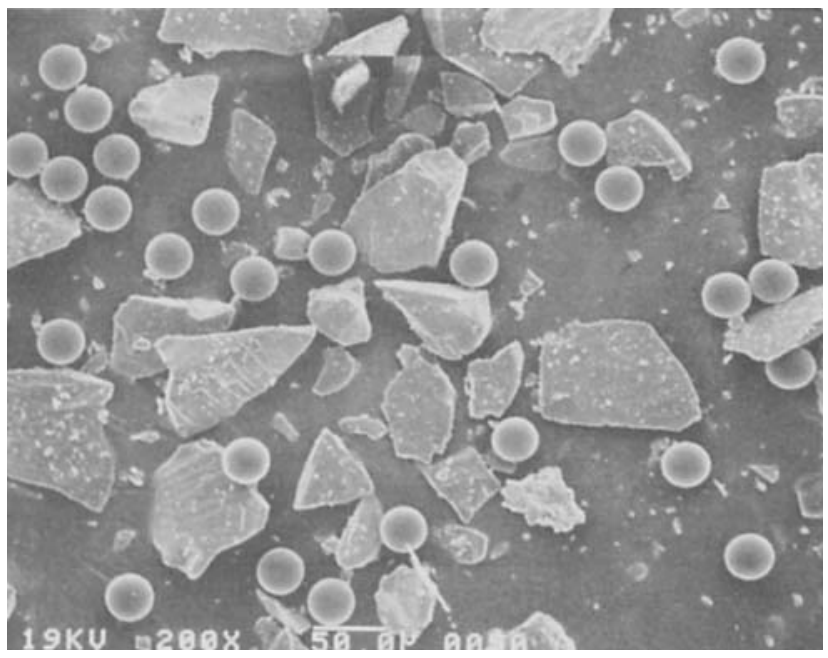

Fig. 1. Scanning electron micrograph of SGM 7 glass powder. The spheres are an internal standard of polystyrene latex of $\sim 30-\mu \mathrm{m}$ diameter.

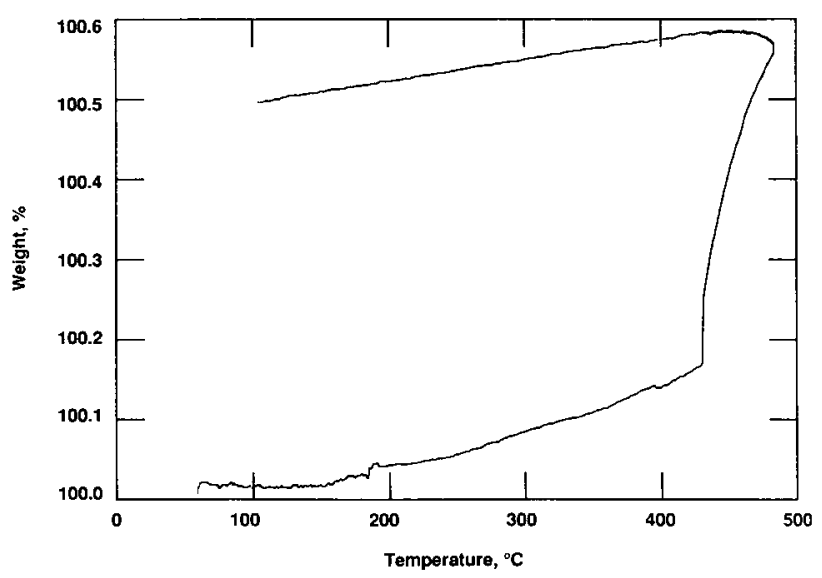

Fig. 2. Profile 1, TGA curve of SGM 7 powdered glass, using oxygen as a purge gas.

Although the data shown in Fig. 4 were from a powdered sample, the powder softens at the higher temperatures of profile 2, causing the particles to coalesce into a thin film of glass in the platinum boat. This is not the case for profile 1 , where the maximum temperature reached is only slightly above the glass transition temperature of the glass. Hence, the sample is still a powder after being subjected to profile 1, although some clumping of the particles was observed. This is probably due to the fact that the glass had reached the softening temperature. It was easily redispersed.

Three sample loadings of powdered SGM 7, purged with oxygen, were run using profile 2 which revealed that the TGA results, in terms of percent weight loss, are not significantly dependent on the amount of material in the platinum boat.

\section{(3) Effect of Purge Gas}

The effect of purge gas on the overall weight gain is significant. For example, using profile 2, the powdered glass sample from SGM 7 showed a weight gain of $\sim 300 \mu \mathrm{g}$ with helium, a gain of $440 \mu \mathrm{g}$ with air, and a gain of $540 \mu \mathrm{g}$ with oxygen. This same general trend is also evident using profile 1 . The flow rate of purge gas also has an effect on the apparent weight gain. At higher helium flow rates of 3 standard cubic feet per hour (compared to the normal flow rate of 0.4 standard cubic feet per hour) the weight gain was further reduced. These results indicate that it is the oxygen in the purge gas that leads to the observed weight gain. It is clear from this study that even with helium purging, significant oxygen uptake can occur. This is due, at least in part, to insufficient removal of oxygen within the TGA apparatus as

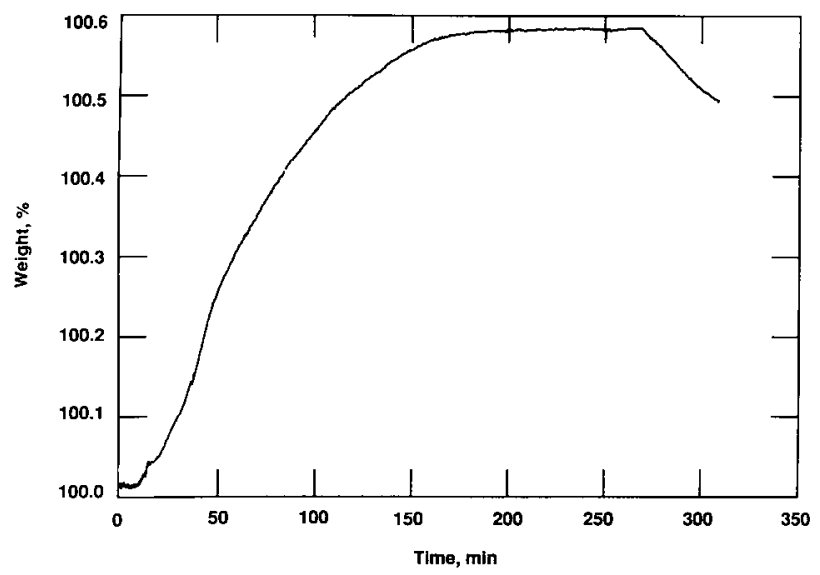

Fig. 3. Profile 1, TGA curve of SGM 7 powdered glass, using oxygen as a purge gas and plotted as percent weight change versus time. Same data as in Fig. 2. 


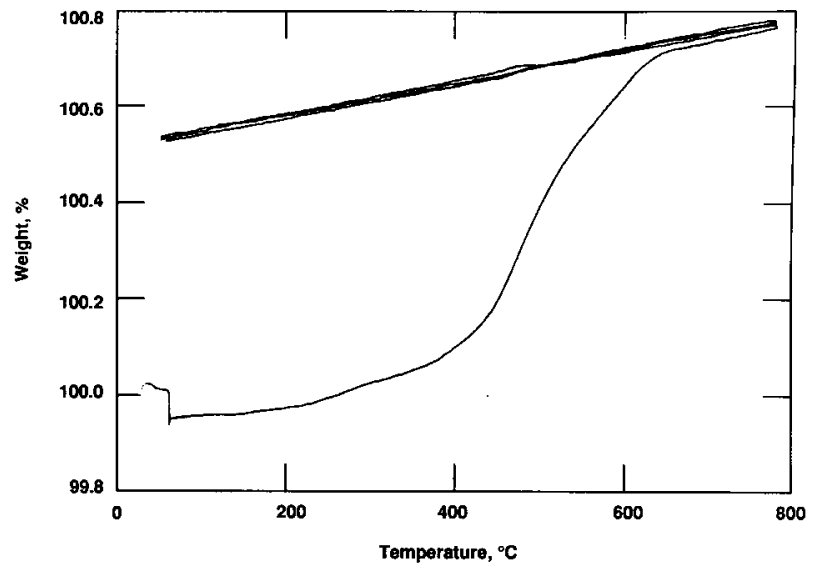

Fig. 4. Profile 2, TGA curve of SGM 7 powdered glass, using oxygen as a purge gas.

reflected by the fact that higher flow rates of helium reduced the weight gains.

There is an additional change which occurs with the amount of oxygen in the purge gas. A small peak near $400^{\circ} \mathrm{C}$ (see Fig. 5) in the heating portion of the cycle is clearly evident in air but much less pronounced in either helium or oxygen. The origin of this peak, which is reproducible and present in all glasses studied, is unknown.

\section{(4) Effect of Waste Glass Composition}

The TGA results on waste glasses from six different SGM runs are presented in Table I. Results were obtained with helium purging using profile 1 at a flow rate of 0.4 standard cubic feet per hour. The reported numbers are the differences between the final and initial weights. For profile 1, samples from campaigns 6 and 8 showed overall weight losses of 100 and $90 \mu \mathrm{g}$, respectively, with heat treatment, while the other four samples all showed gains from 220 to $330 \mu \mathrm{g}$.

The results from profile 2 (Table II) demonstrate that all 6 of the waste glass samples gained weight. As in profile 1, however, glass samples from campaigns 6 and 8 formed a unique subset, which showed the least amount of weight gain. The facts that SGM 6 and SGM 8 glasses gained weight using profile 2 , but lost weight with profile 1 , resulted from exposure to a higher temperature and the use of air for purging with profile 2 .

\section{(5) Effect of Surface Area}

The surface area of the glass sample used has a significant effect on the observed weight changes for both profiles. For

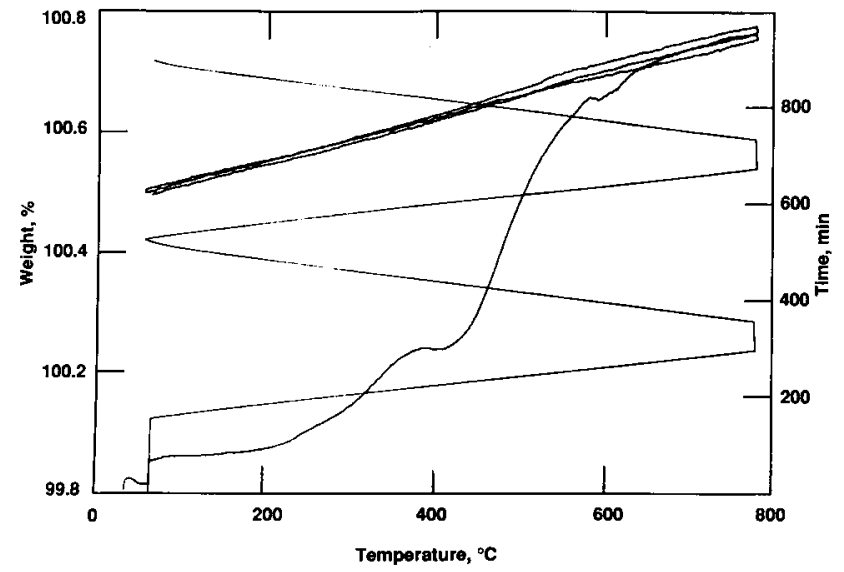

Fig. 5. Profile 2, TGA curve of SGM 7 powdered glass, using air as a purge gas. Note the peak at $\sim 400^{\circ} \mathrm{C}$. The smaller peak at $\sim 600^{\circ} \mathrm{C}$ is an artifact.
Table I. Weight Gain as a Function of the SGM Campaign for Powders Using Profile 1

\begin{tabular}{cc}
\hline SGM & Weight gain (wt\%) \\
\hline campaign & 0.22 \\
5 & -0.1 \\
7 & 0.33 \\
8 & -0.09 \\
9 & 0.25 \\
10 & 0.30 \\
\hline
\end{tabular}

profile 1, large pieces of glass from SGM 7, for example, revealed an overall weight loss of $\sim 15 \mu \mathrm{g}$, using helium as the purge gas, compared to the control experiment in which the empty boat showed a weight loss of $-20 \mu \mathrm{g}$. Within experimental error, then, no weight change was observed for the glass pieces. This is contrasted to the powdered form of the same glass, which showed an overall weight gain of $\sim 400 \mu \mathrm{g}$ under similar conditions. In addition, the weight loss observed in the initial heating cycle of profile 1 with the powder is not observed with the glass pieces.

Table II gives the results of the powdered samples versus glass pieces using profile 2 . In all cases, the weight gain by the pieces was less than that for the powders. To ensure that saturation of the weight gain had occurred with the glass pieces, SGM 7 glass pieces were subjected to a 30 -h heat treatment. No further weight gain was observed during the repeat cycle. It was noted that weight gain with the pieces did not begin until $500^{\circ} \mathrm{C}$, with most of the gain occurring after the temperature reached $800^{\circ} \mathrm{C}$.

With the glass pieces, the initial slope during heating was the same as the final slope during cooling for profile 2 . This is in contrast to the powders, where the initial slope is always less than the final slope (an indication of a weight loss). Hence, the pieces of glass, to the sensitivity of this instrument, do not show any weight loss with either profile.

\section{(6) Sensitivity of TGA Measurement}

The sensitivity of the TGA measurement is defined here as the minimum change in weight which can be determined for these $100-\mathrm{mg}$ samples and is reported in terms of weight percent. For the powders, the sensitivity is also expressed in terms of minimum change in weight per unit surface area. Sensitivity was determined for both powders and pieces using both profiles. In certain cases, sudden changes in the weight greater than the reported sensitivity occurred during the many hours that are required to obtain a TGA curve. However, these changes are random and associated with electrical or mechanical noise and are identifiable by instantaneous change. This noise was reduced by acquiring the data in overnight runs.

For glass powders, the time dependence of the weight change for a profile 1 heat treatment revealed that the weight gain reached a limiting value by the 200 -min mark in the $450^{\circ}$ to $500^{\circ} \mathrm{C}$ temperature range. After this limiting value and during the repeat cycle of this profile, the TGA curve simply followed the baseline within a scatter range of $-10 \mu \mathrm{g}$ for the $100-\mathrm{mg}$ samples. Therefore, after the initial weight loss and

Table II. Weight Gain as a Function of Surface Area Using Profile 2

\begin{tabular}{ccl}
\hline \multirow{2}{*}{$\begin{array}{c}\text { SGM } \\
\text { campaign }\end{array}$} & \multicolumn{2}{c}{ Weight gain (wt\%) } \\
\cline { 2 - 3 } 5 & Powder & \multicolumn{1}{c}{ Pieces } \\
\hline 6 & 0.46 & 0.33 \\
7 & 0.13 & No change \\
8 & 0.45 & 0.30 \\
9 & 0.16 & 0.12 \\
10 & 0.45 & 0.26 \\
\hline
\end{tabular}


the subsequent weight gain, no additional change of weight for the glass was observed in excess of $0.01 \mathrm{wt} \%$.

For the glass pieces or powder subjected to the heat treatment of profile 2 , a scatter of $\sim 10 \mu \mathrm{g}$ was observed after the weight gain reached saturation. Hence, in all cases, the minimum change detected was $10 \mu \mathrm{g}$, corresponding to a sensitivity of $0.01 \mathrm{wt} \%$.

Near the glass transition temperature, volatility is expected to be a surface-controlled property, and therefore the glass volatility in terms of surface area becomes important. Since the BET surface area of the powders is $-0.3 \mathrm{~m}^{2} / \mathrm{g}$, the sensitivity with the powders is $330 \mu \mathrm{g} / \mathrm{m}^{2}$.

\section{(7) TGA of Glass Frits}

Black frit 165 , which was the simulated waste glass feed used in SGM-8, showed a TGA curve of the type shown in Fig. 2 with a weight gain of $\sim 150 \mu \mathrm{g}$. The corresponding 165 white frit, which does not contain iron, showed no weight gain from the TGA curve. An Apec frit, a Cataphote frit, and a Ferro 202, -200 mesh glass frit (these frits contained $\sim 77 \mathrm{wt} \% \mathrm{SiO}_{2}, \sim 8 \mathrm{wt} \% \mathrm{~B}_{2} \mathrm{O}_{3}, \sim 7 \mathrm{wt} \% \mathrm{Li}_{2} \mathrm{O}$, and $\sim 6 \mathrm{wt} \%$ $\mathrm{Na}_{2} \mathrm{O}$ ), all essentially void of iron, showed no weight gain in the TGA experiments but did reveal weight losses of $\sim 0.10 \mathrm{wt} \%(\sim 100 \mu \mathrm{g}), \sim 0.04 \mathrm{wt} \%(\sim 40 \mu \mathrm{g})$, and $\sim 0.2 \mathrm{wt} \%$ $(\sim 200 \mu \mathrm{g})$, respectively. These results reveal that iron must be present within the glass or glass frit in order to observe a weight gain.

\section{Discussion}

\section{(1) Weight Gain}

Weight gain, the dominant feature in the TGA curves of waste glass samples, correlates with the amount of oxygen in the purge stream and the presence of iron in the glass. It therefore appears that the weight gain is due to oxygen uptake. Iron is present in these glass samples in both a reduced form $(\mathrm{FeO})$ and in an oxidized form $\left(\mathrm{Fe}_{2} \mathrm{O}_{3}\right)$. The presence of $\mathrm{FeO}$ provides a means by which uptake of oxygen can occur:

$$
4 \mathrm{FeO}+\mathrm{O}_{2} \rightarrow 2 \mathrm{Fe}_{2} \mathrm{O}_{3}
$$

If this mechanism accounts for the observed weight gain, then the ratio of $\mathrm{Fe}^{2+} / \mathrm{Fe}^{3+}$ in the waste glasses should reflect this. Table III summarizes the $\mathrm{Fe}^{2+} / \mathrm{Fe}^{3+}$ ratios for the waste glasses of this study both before and after heat treatment during the TGA runs. This table reveals that the waste glasses from SGM 6 and SGM 8 have the lowest ratios of $\mathrm{Fe}^{2+} / \mathrm{Fe}^{3+}$, i.e., are the most oxidized. This implies that there is far less $\mathrm{FeO}$ present in the SGM 6 and 8 samples available to react with oxygen. The measured oxygen uptake values (weight gain) for these samples (Table III) are consistent with this ratio. The other samples, with higher ratios, all exhibit significant oxygen uptake.

The values presented in Table III were obtained using profile 1 under different conditions. Thus, SGM 6 and 8 glass powders were run up to $500^{\circ} \mathrm{C}$ in a helium atmosphere, and no weight gain was observed. SGM 9 and 7 glass powders were run in oxygen to maximize the weight gain. The SGM 5 powder was run in helium.

From the weight gain by TGA (measured by adding $100 \mu \mathrm{g}$ to the difference between final and initial weights (see Weight Loss section) and the initial and final ratios of $\mathrm{Fe}^{2+} / \mathrm{Fe}^{3+}$, one can calculate the amount of elemental Fe in the glass. These

Table III. $\mathrm{Fe}^{2+} / \mathrm{Fe}^{3+}$ Ratios in SGM Waste Glass Powders

\begin{tabular}{ccccc}
\hline $\begin{array}{c}\text { SGM } \\
\text { campaign }\end{array}$ & $\mathrm{Fe}^{2+} / \mathrm{Fe}^{3+}$ ratio & Weight gain & \\
\cline { 2 - 4 } Initial & Final & & wt\% Fe \\
\hline 5 & 0.72 & 0.08 & 350 & 7.3 \\
6 & 0.24 & 0.21 & None & \\
7 & 1.70 & 0.25 & 550 & 9.0 \\
8 & 0.22 & 0.19 & None & \\
9 & 0.74 & 0.00 & 440 & 7.3 \\
\hline
\end{tabular}

calculated values are shown in the last column of Table III. These values are close to the amounts of Fe initially fed to the glass melter. For example, the Fe introduced into the melter for SGM 9 was $\sim 7.7$ wt $\%$. Hence, the weight gain observed in these experiments can be accounted for, to first order, by the amount of $\mathrm{Fe}^{2+}$ in these glass samples. (The $\mathrm{Fe}^{2+} / \mathrm{Fe}^{3+}$ ratios obtained from the samples heated in the TGA instrument are only approximate. This is due to the limited amount $(\sim 100 \mathrm{mg})$ of sample available for each analysis.)

The waste glass powders from the six SGM runs were either greenish gray or yellowish brown. The yellowish brown samples from SGM 6 and 8 showed no color change after being heated through profile 1 . The other SGM powders were greenish gray in appearance and underwent a color change to yellow to dark brown after being heated through profile 1 . Hence, the increase in weight is correlated with a color change within the glass. Since $\mathrm{Fe}^{2+}$ is green whereas $\mathrm{Fe}^{3+}$ is rust colored, these color changes are also consistent with reaction (1).

The difference in weight gain as a function of surface area can be rationalized in terms of oxygen diffusion in the particles. For profile 1, very little oxygen uptake occurs with the glass pieces, whereas close to the maximum value of oxygen uptake can be observed with the higher surface area powders. This demonstrates that, even at temperatures near $T_{\mathrm{g}}$, oxygen can diffuse within the bulk of the glass, provided the particle size is small enough. The light scattering and scanning electron micrograph data reveal that the powder consists of polydisperse, irregularly shaped particles with platelike morphology. This implies that the average diffusion length for oxygen under these conditions of time and temperature is much less that the average volumetric particle size of $43 \mu \mathrm{m}$. Half the minimum dimension of each particle is the maximum oxygen diffusion length necessary for oxygen to reach $\mathrm{FeO}$. This dimension, although difficult to determine, appears to be less than $10 \mu \mathrm{m}$ from the scanning electron micrograph data for the larger particles of the powder.

For profile 2 , the glass pieces eventually showed a weight gain which was approximately half that of the powders. During this heat treatment, the glass flowed to form a film on the platinum boat. In spite of the fact that the temperature profile was higher than profile 1 , the diffusion of additional oxygen within this film was limited under these conditions of time and temperature, as evidenced by a smaller weight gain than the powders. This was true even though the glass film was held at $800^{\circ} \mathrm{C}$ for $20 \mathrm{~h}$.

\section{(2) Weight Loss}

The TGA curves for the powdered glass samples showed slopes in the initial heating cycle which were less than the slope of the baseline. This implies that weight loss is occurring during the initial heating of these powdered samples. On the other hand no weight loss, within experimental error, was observed with the larger pieces of glass

The magnitude of the weight loss with the glass powders can be estimated from the results of several experiments. Figures 2 and 4 reveal the initial weight loss for SGM 7 glass powder using both profiles 1 and 2 . The weight loss begins below $100^{\circ} \mathrm{C}$ and ends between $200^{\circ}$ and $300^{\circ} \mathrm{C}$. Extrapolating back to the ordinate using the normal baseline (cooling slope of these curves) gives an intersection near the $0.1 \mathrm{wt} \%$ loss region (a loss of $100 \mu \mathrm{g}$ for the $100-\mathrm{mg}$ sample) for both of these curves. Experiments with empty platinum boats revealed that the weight loss was approximately $20 \mu \mathrm{g}$ $(0.02 \mathrm{wt} \%)$ under these conditions.

A second way to estimate the weight loss is to consider the results of SGM 6 and 8 glass powders heated using profile 1 in helium. Under these conditions, weight gain is essentially precluded and only weight loss is observed. These oxidized powders showed an overall weight loss of $0.1 \mathrm{wt} \%$ for SGM 6 and $0.09 \mathrm{wt} \%$ for SGM 8. This corresponds to losses of 100 and $90 \mu \mathrm{g}$, respectively. 
Finally, TGA experiments using glass frit samples revealed a weight loss in the range from 0 to $0.2 \mathrm{wt} \%$. These glass frit samples contained no iron and consequently exhibited no weight gain. Therefore, the only change that occurred was due to weight loss.

The conclusions from these three experiments are that the weight loss with the glass powders is $\sim 0.1 \mathrm{wt} \%$ and that it occurs at relatively low temperatures (less than $300^{\circ} \mathrm{C}$ ).

This weight loss with the powders can be explained as follows. The glass powder has a surface area 600 times greater than the surface area of the glass pieces $\left(5 \times 10^{-4} \mathrm{~m}^{2} / \mathrm{g}\right)$. During the milling process for producing the powder, water from the atmosphere can adsorb onto the newly formed surfaces of the particles (reaction (2)). The amount of water adsorbed is directly proportional to the specific surface area of the powder. A weight loss is then observed in the TGA experiments when the powder is heated (reaction (3)). This weight loss is

$$
\begin{aligned}
& \text { powder }+\mathrm{H}_{2} \mathrm{O} \rightarrow \text { (powder }^{\text {adsorbed } \mathrm{H}_{2} \mathrm{O}} \\
& \text { (powder) }^{\text {adsorbed } \mathrm{H}_{2} \mathrm{O}}+\text { heat } \rightarrow \text { powder }+\mathrm{H}_{2} \mathrm{O}
\end{aligned}
$$

due to the desorption of the adsorbed water. The fact that the weight loss occurs at relatively low temperatures (see Figs. 2 and 4) is also consistent with desorption of weakly adsorbed water from the glass surface. In terms of surface area, the desorption of adsorbed water from the surface of the glass pieces should be 600 times less than this, or $0.17 \mu \mathrm{g}$ for a 100 -mg sample. This is well below the sensitivity of the TGA measurement.

The weight loss due to water desorption and the weight gain due to oxygen uptake have the potential to mask the true volatility of the waste glass. However, water desorption occurred at temperatures between $50^{\circ}$ and $300^{\circ} \mathrm{C}$ and consequently did not interfere with measurements near $T_{\mathrm{g}}$. Also, certain powdered samples could be run under conditions where no weight gain was observed. In these cases no volatility was observed at $T_{\mathrm{g}}$. For those samples which gained weight, no further changes in weight due to volatility were observed after weight gain due to oxygen uptake had stopped. These results suggest that masking does not alter the conclusion that glass volatility is less than $0.01 \mathrm{wt} \%$ at $T_{\mathrm{g}}$.

It was demonstrated that the presence of oxygen does not effect the volatility of the glass samples. That is, the volatility, whatever its value, is still less than the detection level, independent of the oxygen concentration in the purge gas. Since the compressed air used in these experiments has a relative humidity of $\sim 30 \%$, the same arguments can be made for the lack of an effect of water on the glass volatility for a relative humidity value of $30 \%$ (both the helium and oxygen are dry). The relative humidity values in the canisters are expected to be less than this value, ${ }^{3}$ while the oxygen level will most likely be close to that of air $(-20 \%)$.

\section{(3) Defense Waste Processing Facility Canister Volatility}

The fact that glass volatility is less than $0.01 \mathrm{wt} \%$ or $330 \mu \mathrm{g} / \mathrm{m}^{2}$ can be used to estimate an upper limit of the volatility within a Defense Waste Processing Facility canister heated to $T_{\mathrm{g}}$. A monolith of glass (a cylinder of 2.4-m height with a radius of $0.3 \mathrm{~m}$ ) weighing $1700 \mathrm{~kg}$ inside a Defense Waste Processing Facility canister has a geometric surface area of $\sim 5 \mathrm{~m}^{2}$. Due to cracking of the glass, ${ }^{24}$ this surface area can increase by a factor of 25 , giving a total surface area of glass within the canister of $125 \mathrm{~m}^{2}$. Therefore these TGA experiments give an upper limit for volatility of $41.3 \mathrm{mg}$ for a single canister, at $T_{\mathrm{g}}$.

\section{Conclusions}

This work has demonstrated that simulated high-level waste glass uptakes oxygen during heat treatment. This oxygen uptake is explained completely by the oxidation of $\mathrm{FeO}$ to $\mathrm{Fe}_{2} \mathrm{O}_{3}$. Hence the weight gain is controlled by the amount of
$\mathrm{FeO}$ in the glass and the availability of oxygen. For these SGM waste glass samples, the maximum weight gain was $\sim 0.55 \mathrm{wt} \%$. With glass powders, there is significant uptake in the temperature range from $200^{\circ}$ to $500^{\circ} \mathrm{C}$. With glass pieces, significant oxygen uptake begins near $500^{\circ} \mathrm{C}$, with most of the weight gain occurring at temperatures near $800^{\circ} \mathrm{C}$. These differences in oxygen uptake between the powders and the pieces can be explained by the oxygen diffusion length at these temperatures.

These same waste glass samples also exhibit a weight loss if the sample is in powdered form. This loss is most likely due to the desorption of $\mathrm{H}_{2} \mathrm{O}$ which had adsorbed onto the newly created surface during the milling of the glass into the powder. The loss is estimated to be between 0.05 and $0.1 \mathrm{wt} \%$, which corresponds roughly to 0.5 to 1 water molecule $/ \AA^{2}$.

All of the scale glass melter glass samples ${ }^{19}$ showed true volatilities less than $0.01 \mathrm{wt} \%$. This is equivalent to a maximum weight loss through volatilization of $330 \mu \mathrm{g} / \mathrm{m}^{2}$ of glass surface. For a canister, this translates into an upper limit for the volatility of $41.3 \mathrm{mg}$ released within a single canister as a result of heating the canister to $T_{\mathrm{g}}$. Hence, it may be concluded that any free liquids, free gases, combustibles, pyrophorics, and explosives released upon heating the waste glass to $T_{\mathrm{g}}$ were also less than the detection limit of $330 \mu \mathrm{g} / \mathrm{m}^{2}$ of glass surface, or $41 \mathrm{mg} /$ canister.

The lack of organics within the waste glass was demonstrated by the fact that heating the SGM waste glass powders and pieces (containing different amounts of organics in the feed) in oxygen up to $800^{\circ} \mathrm{C}$ did not give rise to detectable volatility. Under these conditions, organic compounds would burn to carbon dioxide and other volatile compounds, which would lead to an observable weight loss. This limits the amount of organics to be less than or equal to the detection limit of 0.01 wt\%.

These results will be used to demonstrate that the Defense Waste Processing Facility is in compliance with the Waste Acceptance Preliminary Specifications.

Acknowledgments: All the data presented here on TGA were acquired by A. B. Ray. W. J. Kerrigan provided guidance in the acquisition and interpretation of the TGA data. D.F. Steedly carried out the SEM work, while J.T. Hunter determined the particle size distribution. R. A. Malstrom measured the BET surface areas. Glass samples were obtained from C.M. Jantzen, N. E. Bibler, W. G. Ramsey, and R. F. Schumacher. D. C. Beam generated the powdered glass samples. C. M. Jantzen pointed out the mechanism given in Eq. (1) and W. G. Ramsey suggested measuring the $\mathrm{Fe}^{2+} / \mathrm{Fe}^{3+}$ ratio, which was subsequently performed by N.S. Wallace. M. J. Plodinec provided guidance throughout this work.

\section{References}

'Office of Civilian Radioactive Waste Management, "Waste Acceptance Preliminary Specifications of the Defense Waste Processing Facility HighLevel Waste Form," U.S. DOE Report No. OGR/B-8, Rev. 1, February 1988.

${ }^{2}$ U.S. Department of Energy, Savannah River Site, "Defense Waste Processing Facility Waste Form Compliance Plan," U.S. DOE Report No. WSRC-SW4-6, March 1990

${ }^{3}$ J. R. Harbour, T. J. Miller, and M. J. Whitaker, "Exclusion of Foreign Materials from SRS Canistered Waste Forms: Characterization of the Gas within the Free Volume"; in Proceedings of the 1991 International High-Level Radioactive Waste Management Conference, Las Vegas, NV, 1991. American Nuclear Society, LaGrange Park, IL and American Society of Civil Engineers, New York.

${ }^{4}$ W. J. Gray, "Volatility of a Zinc Borosilicate Glass Containing Simulated High-Level Radioactive Waste,” U.S. DOE Report No. BNWL-2111, 1976; W. J. Gray, "Volatility of Some Potential High-Level Radioactive Waste Forms," Radioact. Waste Manage., 1, 147 (1989).

${ }^{5}$ D. Walmsley, B. A. Sammons, and J. R. Grover, "Volatility Studies of Glasses for the FINGAL Process," Report No. AERE-R 5777. Atomic Energy Research Establishment, Harwell, U.K., July 1969.

${ }^{6}$ G. W. Wilds, "Vaporization of Semi-Volatile Components from Savannah River Plant Waste Glass," U.S. DOE Report No. DP-1504, 1978.

${ }^{7}$ H. Kamizono, S. Kikkawa, Y. Togashi, and S. Tashiro, "Volatilization of ${ }^{137} \mathrm{Cs}$ and ${ }^{106} \mathrm{Ru}$ from Borosilicate Glass Containing Actual High-Level Waste," J. Am. Ceram. Soc., 72 [8] 1438-41 (1989).

${ }^{8}$ H. Kamizono, S. Kikkawa, S. Tashiro, and H. Nakamura, "Volatilization of Cesium from Nuclear Waste in a Canister," Nucl. Technol., 72, 84-88 (1986).

${ }^{9}$ H. Kamizono, S. Kikkawa, S. Tashiro, N. Nakamura, and H. Kanazawa, "Air Contamination by Cesium in a Canister Containing Nuclear Waste Glass," J. Nucl. Mater., 149, 113-16 (1987). 
'0D.W. Bonnell, E. R. Plante, and J.W. Hastie, "Vaporization of Simulated Nuclear Waste Glass," J. Non-Cryst. Solids, 84, 268-75 (1986).

"J.W. Hastie, E. R. Plante, and D.W. Bonnell, "Vaporization of Simulated Nuclear Waste Glass," Report No. NBSIR 83-2731. National Bureau of Standards, Washington, DC.

${ }^{12} \mathrm{M}$. Asano and Y. Yasue, "Mass Spectrometric Study of the Vaporization of Sodium Borosilicate Glasses," J. Nucl. Mater., 138, 65-72 (1986).

${ }^{13} \mathrm{M}$. Asaro and Y. Yasue, "Vapor Species over $\mathrm{Na}_{2} \mathrm{O}-\mathrm{B}_{2} \mathrm{O}_{3}-\mathrm{SiO}_{2}-\mathrm{Cs}_{2} \mathrm{O}$ Glass," J. Nucl. Sci. Technol., 22, 1029-32 (1985).

${ }^{14}$ M. Asano and T. Kou, "Vaporization of Sodium-Rubidium Borosilicate Glasses," Phys. Chem. Glasses, 30, 39-45 (1989).

${ }^{15}$ M. M. Shultz, V. L. Stolyarova, and G. A. Semenov, "Mass Spectrometric Study of Thermodynamic Properties and Vaporization Processes in the $\mathrm{Na}_{2} \mathrm{O}-\mathrm{B}_{2} \mathrm{O}_{3} \ldots \mathrm{GeO}_{2}$ Glass-Forming Melts," J. Non-Cryst. Solids, 38-39, 581$86(1980)$.

${ }^{16}$ G.W. Wilds, "Vaporization of Semi-Volatile Components from Savannah River Plant Waste Glass," U.S. DOE Report No. DP-1504, 1978.

${ }^{17}$ J.T. Wenzel and D. M. Sanders, "Sodium and Boron Vaporisation from a
Boric Oxide and a Borosilicate Glass Melt," Phys. Chem. Glasses, 23, 47-52 (1982).

${ }^{18}$ R. Terai and E. Kosaka, "Volatilization of Low Temperature Borosilicate Glasses for High-Level Radioactive Wastes at Elevated Temperatures," Osaka Kogyo Gijutsu Shikensho Kiho, 27, 150-56 (1976).

${ }^{19} \mathrm{C}$. M. Jantzen, "Glass Compositions and Frit Formulations Developed for Defense Waste Processing Facility," U.S. DOE Report No. DPST-88-952, 1988.

20"Instruction Manual, Du Pont 950 Thermogravimetric Analyzer," Manual No. G-125. E.I. du Pont de Nemours \& Co., Wilmington, DE.

${ }^{21} \mathrm{C}$. Duval, Inorganic Thermogravimetric Analysis, 2 nd and revised ed.; p. 281. Elsevier Publishing Co., Barking, Essex, U.K., 1963.

${ }^{22}$ A. E. Newkirk, "Thermogravimetric Measurements," Anal. Chem., 32, $1558(1960)$.

${ }^{23} \mathrm{E}$.W. Baumann, "Colorimetric Determination of Ferrous/Ferric Ratio in Glass," U.S. DOE Report No. DPST-87-304, 1987.

${ }^{24}$ M. J. Plodinec, "Glass Fracture and Defense Waste Processing Facility Product Performance," U.S. DOE Report No. DPST-89-220, 1989. 